\title{
Acceso a la información pública y autodeterminación informativa: publicidad de las remuneraciones de los altos ejecutivos de las empresas públicas. El caso de TVN
}

\author{
Access to Public Information and Informational Self- \\ determination: Publicity of Top Executives Salaries in State- \\ owned Companies. The TVN Case
}

MONTSERRAT CASTRO HERMOSILLA

Facultad de Derecho, Universidad de Chile

ANA MARÍA MUÑOZ MASSOUH

Facultad de Comunicaciones, Pontificia Universidad Católica de Chile

RESUMEN El trabajo analiza la opinión del Tribunal Constitucional chileno sobre la aplicación de la Ley de Transparencia y sus efectos sobre el derecho a la privacidad de los trabajadores de empresas públicas creadas por ley. En particular, se revisará la sentencia de este Tribunal que dispuso la publicidad de las remuneraciones de los altos ejecutivos de Televisión Nacional de Chile.

PALABRAS CLAVE Transparencia, privacidad, autodeterminación informativa, empresas públicas.

ABSTRACT This paper analyzes the opinion of the Chilean Constitutional Court about the application of the Transparency Act and its effects on the protection of workers' privacy rights in state-owned companies. In 
particular it reviews the Court's judgment regarding to the publication of top executives salaries from Chile's public television broadcaster.

KEYWORDS Transparency, privacy, informational self, determination, state-owned companies.

\section{ANTECEDENTES PRELIMINARES}

Conforme al artículo io. ${ }^{\circ}$ de la ley 20.285 sobre Acceso a la Información Pública (en adelante, «Ley de Transparencia»), el principio de transparencia en la función pública es aplicable a las empresas públicas creadas por ley y a las empresas del Estado. Así, en virtud de dicho principio, estas empresas deben mantener a disposición permanente del público, a través de sus sitios electrónicos, toda remuneración percibida en el año por cada director, presidente ejecutivo o vicepresidente ejecutivo y gerentes responsables de la dirección y administración superior de la empresa.

Por otra parte, el artículo $33 .^{\circ}$ de la Ley de Transparencia dispone que el Consejo para la Transparencia (en adelante, el «Consejo») tendrá entre sus funciones resolver, fundadamente, los reclamos por denegación de acceso a la información que le sean formulados de conformidad a la ley.

En virtud de dichas atribuciones, con fecha 23 de diciembre de $2009^{1}$ el Consejo acordó requerir a Televisión Nacional de Chile (TVN) la publicación en su sitio web de toda remuneración percibida por los gerentes responsables de su dirección y administración superior, en el entendido que ellos serían los «directivos capaces de determinar los objetivos, planificar, dirigir o controlar la conducción superior de los negocios o la política estratégica de la entidad» sin atender a la calidad, forma o modalidad laboral o contractual bajo la cual el directivo esté relacionado con la entidad, ni el título o denominación de su cargo o trabajo. Ante ello, TVN y los ejecutivos afectados interpusieron dos recursos de inaplicabilidad ante el Tribunal Constitucional alegando la inconstitucionalidad en el caso concreto del literal h) del artículo so. ${ }^{\circ}$ y del literal b) del artículo $33 .^{\circ}$, ambos de la ley 20.285 .

I. Decisión amparo rol nro. I 5-09. 
La sentencia en análisis ${ }^{2}$ tuvo por objeto resolver la controversia suscitada a propósito del acuerdo adoptado por el Consejo que, amparándose en el literal b) del artículo $33 .^{\circ}$ de la Ley de Transparencia, ordenó a TVN hacer públicas las remuneraciones de ciertos ejecutivos del canal que no se encuentran expresamente obligados por la referida norma. Todo ello, en razón que el efecto que produciría la decisión del Consejo vulneraría los artículos $19 .^{\circ}$ número 2 y número 4 y el artículo $19 .{ }^{\circ}$ número 2 I de la Constitución Política de la República.

\section{PROBLEMA CONSTITUCIONAL PLANTEADO POR LOS REQUIRENTES}

Para fundamentar su acción, los requirentes señalaron, en primer lugar, que la aplicación de las normas sobre transparencia activa a los altos ejecutivos de TVN infringía el derecho a la privacidad, garantía que se encuentra establecida en el artículo I9. ${ }^{\circ}$ número 4 de la Constitución, dado que ello significaría la revelación de información confidencial relativa a las remuneraciones de su plana ejecutiva.

Adicionalmente, indicaron que dicha regla de confidencialidad se encuentra incorporada en sus contratos de trabajo, la cual es preexistente a la norma de la ley 20.285 que se impugna; y que la aplicación de la misma vulnera lo dispuesto en el artículo 22. ${ }^{\circ}$ de la Ley sobre Efecto Retroactivo de las Leyes referente a que «en todo contrato se encuentran incorporadas las leyes vigentes al tiempo de su celebración». En consecuencia, en el caso concreto, la preeminencia de la vida privada configuraría precisamente una de las excepciones a que se refiere el inciso segundo del artículo $8 .^{\circ}$ de la Constitución.

Por otra parte, precisan que la aplicación de los preceptos impugnados sería inconstitucional en razón que no se cumpliría en tal caso con la finalidad prevista por el legislador al establecer el deber de transparencia activa tratándose de TVN; y, en consecuencia, se infringirían las garantías contenidas en los numerales 2 y 2 I del artículo r 9. ${ }^{\circ}$ de la Constitución, en relación con el estatuto legal de las demás concesionarias de televisión abierta, ya que se estaría estableciendo una diferencia arbitraria a su respecto en relación con las demás concesionarias, al sometérsela sólo a ella al Consejo para la Transparencia y obligarla a revelar infor-

2. Sentencia del Tribunal Constitucional rol I732-IO-INA y I 800-IO-INA (acumulados). 
mación confidencial y sensible de sus trabajadores, sin hacer extensiva dicha obligación a las demás entidades, alterando en consecuencia su libre competencia en el mercado.

Así, señalan que el artículo $35 .^{\circ}$ de la ley I9.I 32 excluye a TVN de las normas legales "generales o especiales que rigen o rijan en el futuro a las empresas del Estado», salvo disposición legal expresa, y que el artículo $24 .^{\circ}$ de la misma norma la sujeta a idénticas normas financieras y tributarias que rigen para las sociedades anónimas abiertas, sin que se le aplique el régimen de administración económica de las empresas del Estado; adicionalmente señala que el artículo 29. ${ }^{\circ}$ de la mencionada ley dispone que sus trabajadores se rijan exclusivamente por las normas del Código del Trabajo, siendo considerados como trabajadores del sector privado.

Por su parte, el Consejo se refiere en sus alegaciones a que la aplicación de los preceptos cuestionados no vulnera el derecho a la vida privada, pues el ejercicio de dicho derecho se encontraría limitado por el ejercicio de otro derecho fundamental: el derecho de acceso a la información pública.

Tampoco se infringiría el artículo I9. ${ }^{\circ}$ número 2 I de la Constitución, toda vez que dicha norma establece derechos a favor de los particulares y no de las empresas públicas; y, finalmente, que no se vulneraría la garantía contenida en el artículo I9. ${ }^{\circ}$ número 2 de la Constitución en la medida en que el estatuto diferenciado a que se somete TVN respecto de otras concesionarias de televisión abierta se justificaría por razones de interés público, transparencia y probidad.

\section{RAZONAMIENTO DEL TRIBUNAL}

Cabe hacer presente que la mayoría de los ministros señaló que el requerimiento debía ser rechazado puesto que la discusión sobre si se aplican las normas de transparencia y publicidad a las empresas públicas constituye una cuestión de mera legalidad. De esta forma, el voto de mayoría previene antes de entrar a conocer el fondo del asunto que el conflicto sometido a su decisión no es asunto de su competencia ya que corresponde a cuestiones de mera legalidad, tarea que corresponde a los respectivos jueces del fondo, quienes son los llamados a encontrar la solución de eventuales conflictos entre leyes y determinar que preceptos 
deben ser aplicados para poner término al litigio sometido a su consideración (considerando $3 .^{\circ}$ ). Cabe hacer presente que este criterio ha sido utilizado por el Tribunal en otras oportunidades (entre otros, roles números I2 I 4, I 220).

Sin perjuicio de lo anterior, el Tribunal señala que la aplicación del artículo IO. $^{\circ}$ letra h) de la ley 20.285 no contraviene el artículo I9. ${ }^{\circ}$ número 4 de la Constitución puesto que el derecho a la vida privada no tiene, como es evidente, carácter absoluto, encontrándose el legislador habilitado para regular su ejercicio, sujetándose eso sí a lo que dispone la Carta Fundamental. Así, en el caso en cuestión, la mayoría entiende que la aplicación del artículo ıo. ${ }^{\circ}$ de la Ley de Transparencia permite dar publicidad al destino de los recursos que las empresas públicas utilizan en remunerar a su planta directiva. El conocimiento de tales remuneraciones y el de las que correspondan a los funcionarios del Estado presentaría un innegable interés público. Para la mayoría, la publicidad de las remuneraciones de los requirentes se exige en razón del alto cargo que desempeñan en TVN y de la naturaleza de la empresa que dirigen, no en tanto sujetos particulares corrientes.

En este sentido, la mayoría concluye que la protección a la vida privada cede en aquellos casos en que se encuentran involucrados intereses legítimos de la comunidad - en el caso concreto, la probidad- al ocupar dichas personas altos cargos en una entidad pública.

A continuación, el Tribunal indica que tampoco se vulnera el artículo I $9 .^{\circ}$ número 2 I inciso $2^{\circ}$, puesto que los preceptos legales impugnados cumplen con el quórum de aprobación exigido por dicha norma y, además, responden a un interés legítimo. Así, al tenor de lo dispuesto en el artículo I9. ${ }^{\circ}$ número $2 \mathrm{I}$ de la Constitución y el Estatuto de TVN, esta última se rige por la legislación común aplicable a los particulares. Sin perjuicio de ello, el propio legislador estableció una excepción y le hace aplicable ciertas normas referidas al régimen de transparencia activa.

Concluye el voto de mayoría señalando que al haber sido dicha excepción aprobada con el quórum calificado que la Constitución exige y teniendo presente motivos calificados que justifiquen dicho régimen (todo ello en correspondencia con los principios de publicidad y acceso a la información reconocidos en los artículos $8 .^{\circ}$ y I $9 .^{\circ}$ número I 2 de la Carta Fundamental), ésta se encuentra legitimada.

En razón de lo expuesto, el Tribunal rechaza los requerimientos de 
inaplicabilidad por inconstitucionalidad interpuestos por TVN y por los ejecutivos afectados por la decisión del Consejo.

\section{VOTO DE MINORÍA DEL MINISTRO CARLOS CARMONA}

El ministro Carmona articula su voto disidente sobre la base de la vulneración de dos normas constitucionales, a saber, el derecho a la privacidad reconocido en el artículo I9. ${ }^{\circ}$ número 4 y el derecho a la libertad económica garantizada en el artículo I9. ${ }^{\circ}$ número 2 I.

\section{VULNERACIÓN DE LA VIDA PRIVADA}

Para el ministro disidente, dicha norma adolece de inconstitucionalidad, en el caso concreto, por afectar el control que tienen las personas sobre un dato de su vida privada: su remuneración. Sin perjuicio de ello, el ministro Carmona advierte que este derecho a la privacidad no es absoluto y su garantía no permite ser extendida a todo evento. En palabras suyas, «no es que la sociedad no tenga la facultad para inmiscuirse en ciertos aspectos de la vida de las personas». Para el ministro hay razones que justifican que las personas no puedan excluir ciertas invasiones de su esfera privada, debiendo soportar algunas intromisiones no deseadas. «Lo que sucede es que la persona, junto con esta dimensión negativa o pasiva de la vida privada, que le permite en ciertos casos excluir a terceros de ciertos ámbitos, tiene una dimensión activa o dinámica, de control y defensa de cierta información de su vida, de modo que pueda controlar su circulación. Es lo que se denomina la autodeterminación informativa». Sin embargo, para el ministro, en el caso concreto, la norma objetada es extremadamente gravosa para los sujetos afectados.

Resulta interesante destacar que el voto disidente relaciona la protección de la vida privada con la ley I9.628 sobre Protección de la Vida Privada, al poner de manifiesto la vulneración que se produciría al obligar a TVN a hacer pública «toda remuneración» y publicar esa información en sitios web «actualizados» y "a disposición permanente», «en forma completa» $\mathrm{y}$ «de modo que permita su fácil identificación y un acceso expedito».

De hecho, dicha ley señala en su artículo $4 .^{\circ}$ inciso I. ${ }^{\circ}$ que para procesar los datos de una persona se requiere del consentimiento de su titu- 
lar. Sin embargo, el inciso $5 .^{\circ}$ de dicho artículo agrega que no requiere autorización el tratamiento de datos personales que provengan o que se recolecten de fuentes accesibles al público.

Una reflexión similar realiza en su opinión de minoría a la sentencia rol nro. $\mathrm{I} 894,{ }^{3}$ al identificar como el objeto de resguardo de la mencionada ley sobre Protección de la Vida Privada, el denominado «derecho a la autodeterminación informativa», señalando que la referida ley «se encarga de proteger a las personas de la circulación de la información que sobre ellas mismas existe en distintos centros de acopio. Dicho derecho es la dimensión activa del derecho a la vida privada. Mientras la vida privada era concebida clásicamente como la no interferencia ilegítima en la vida personal, se entendía de una manera pasiva. Era el derecho a no ser molestado. El derecho a la autodeterminación, en cambio, implica controlar los datos que circulan sobre cada uno de nosotros».

Entonces, previene el ministro Carmona al unir lógicamente ambas disposiciones, a saber, el artículo I0. ${ }^{\circ}$ letra h) de la ley 20.285 y el artículo $4{ }^{\circ}$ de la ley 19.628 , cualquier persona podrá no sólo acceder a esta información, sino también emplearla para cualquier tratamiento de datos personales, sin autorización alguna de sus titulares.

En segundo lugar, y en complemento de lo anterior, agrega el ministro que dicha esfera privada se encuentra reforzada tratándose de remuneraciones pactadas en el marco del Código del Trabajo, ya que las remuneraciones de los ejecutivos requirentes fueron definidas en cuanto a su «monto, forma y período de pago» por un contrato de trabajo, no por una ley. Por lo tanto, no estamos frente a una relación estatutaria, en que el legislador puede libremente establecer derechos y obligaciones.

\section{ANÁLISIS DE LA SENTENCIA}

El principio de transparencia constituye un elemento esencial en el desarrollo de un sistema democrático ya que permite a la ciudadanía conocer los fundamentos y el modo en que actúa la administración pública, pudiendo evaluar y fiscalizar el cumplimiento por parte de ésta del prin-

3. Control de constitucionalidad del proyecto de ley que sanciona el acoso sexual de menores, la pornografía infantil y la posesión de material pornográfico infantil (Boletín 5837-07). Ley 20.526. 
cipio de probidad; además, disminuye las posibilidades de actuaciones corruptas o deshonestas por parte de los administradores; $y$, en consecuencia, permite la participación activa de la sociedad civil en la gestión pública.

En razón de ello, la ley I9.653, que modificó la Ley Orgánica Constitucional de Bases Generales de la Administración del Estado (LOCBGAE), reguló inicialmente el acceso a la información pública al permitir el acceso a los actos administrativos y a los documentos que le servían de complemento directo y esencial.

Con el propósito de reforzar este principio, el Senado instó por la incorporación de un nuevo artículo $8 .^{\circ}$ a la Constitución que redujera la discrecionalidad administrativa, de manera que fuera la ley la que estableciera las hipótesis de secreto o reserva.

De este modo, la actual norma constitucional sólo permite restringir la publicidad de los actos y resoluciones estatales (sus fundamentos y procedimientos) cuando una ley de quórum calificado así lo autorice, fundándose en alguna de las siguientes circunstancias: i) el debido cumplimiento del funcionamiento de los órganos del Estado; ii) los derechos de las personas; iii) la seguridad de la Nación, o; iv) el interés nacional. Así, el objetivo del constituyente del 2005 fue excluir la posibilidad que se declarasen secretos o reservados ciertos actos de la administración, por una vía distinta a la ley de quórum calificado. De lo anterior podemos concluir que la reforma constitucional del año 2005 tuvo por objeto consagrar en el artículo $8 .^{\circ}$ el principio de publicidad de los actos de la administración; en este sentido, la Constitución estableció como únicas excepciones las causales recién referidas.

Por otra parte, la moción parlamentaria que dio origen a la Ley de Transparencia tuvo por objeto consagrar el derecho de acceso a la información pública (estableciendo distintos mecanismos) y estableciendo un sistema de amparo ante la negativa de los órganos a entregar dicha información. En este sentido, la referida norma regula la transparencia de los órganos de la Administración del Estado, el derecho de acceso a la información que se encuentra en poder de dichos órganos, los procedimientos para su ejercicio y el sistema de amparo del mismo.

Sobre el particular, es relevante destacar que durante la discusión del proyecto de ley respecto de qué instrumentos serían públicos, el Senado acordó que sólo lo serían aquellos instrumentos relacionados con la 
dictación de un acto administrativo, que produce efectos jurídicos, excluyéndose aquellos otros que no cumplían con estos requisitos. De este modo, la Ley de Transparencia es clara en señalar que su objeto es que «la función pública se ejerza con transparencia, de modo que permita y promueva el conocimiento de los procedimientos, contenidos y decisiones que se adopten en ejercicio de ella».

En dicho sentido, el inciso $2 .^{\circ}$ de su artículo $4 .^{\circ}$ al describir el principio de transparencia señala que «consiste en respetar y cautelar la publicidad de los actos, resoluciones, procedimientos y documentos de la Administración, así como la de sus fundamentos, y en facilitar el acceso de cualquier persona a esa información, a través de los medios y procedimientos que al efecto establezca la ley».

Por lo tanto, antes de comenzar con el análisis de la sentencia, cabe definir el escenario en que se sitúa el conflicto constitucional objeto del requerimiento. Para ello, es necesario distinguir tres principios: probidad, publicidad y transparencia, los cuales están contenidos en distintas disposiciones. Así, el principio de probidad se encuentra recogido en el artículo $8 .^{\circ}$ inciso $\mathrm{r} .{ }^{\circ}$ de la Constitución; el principio de publicidad de los actos de la Administración en el inciso 2. ${ }^{\circ}$ del mismo artículo; y el derecho al acceso a la información pública se encuentra garantizado en el artículo го.$^{\circ}$ de la ley 20.285 , el cual además está implícitamente consagrado en la garantía sobre libertad de expresión contenida en el artículo I9. ${ }^{\circ}$ número I 2 de la Constitución.

Para el análisis que efectuaremos a continuación tal distinción es clave y, como señalaremos, no fue debidamente considerada por la mayoría del Tribunal al fundamentar el rechazo del requerimiento.

\section{LA PROTECCIÓN DE LA VIDA PRIVADA TAMBIÉN COMPRENDE ASPECTOS VINCULADOS AL PATRIMONIO DE UNA PERSONA}

\section{CONSIDERACIONES PRELIMINARES}

Como antecedente, cabe señalar que antes del texto constitucional, la única dimensión de tutela de la vida privada en nuestro ordenamiento constitucional era la inviolabilidad del domicilio y el secreto de la correspondencia, los cuales también se encontraban amparados penalmente bajo los tipos descritos en el Código Penal, que sancionaba la violación 
de morada y de correspondencia (Anguita, 2009). Hoy, el artículo I9. ${ }^{\circ}$ número 4 de la Constitución asegura a todas las personas «el respeto y protección de la vida privada y la honra de la persona y su familia».

Sobre el particular, la privacidad de las personas es entendida como «una manifestación jurídica de la dignidad y respeto que se debe a todo individuo de la especie humana» (Vivanco, 2006: 345); Corral la ha descrito como un bien jurídico, señalando:

[Consiste en] la posición de una persona (o entidad colectiva personal) en virtud de la cual se encuentra libre de intromisiones o difusiones cognoscitivas de hechos que pertenecen a su interioridad corporal y psicológica o a las relaciones que ella mantiene o ha mantenido con otros, por parte de agentes externos que, sobre la base de una valoración media razonable, son ajenos al contenido y finalidad de dicha interioridad o relaciones (Corral, 2000: 347 ).

Por otra parte, al igual que en nuestro ordenamiento, en el derecho comparado el contenido del concepto de derecho a la privacidad se encuentra en plena etapa de elaboración.

Así, en el derecho angloamericano ha ido extendiendo su irradiación, por vía jurisprudencial, hacia ámbitos que pudieron haber parecido insospechados para los primeros sostenedores de la moderna teoría de la privacy, y su misma evolución presenta en el derecho americano problemas variados y muy discutidos por la doctrina. En el derecho continental europeo ha recibido distintas denominaciones y así se habla de «riservatezza», «derecho a la vida privada», «derecho a la intimidad», «derechos pertenecientes a la esfera de la vida privada», etc. (Suárez Crothers, 2000: I03).

Al respecto, cabe señalar que el concepto de vida privada ha evolucionado en el tiempo, entendiéndose actualmente no sólo referido a aquellos espacios físicos que queramos resguardar del conocimiento de otros, sino que alcanza hasta donde lleguen nuestras legítimas expectativas de privacidad. Como indican algunos autores, la protección de la vida privada consiste en resguardar «la integridad de la dignidad humana, por medio del amparo de una de las variadas manifestaciones de la personalidad» (Novoa Monreal, I989: 54).

Por ello, si se revisa la doctrina más reciente, podemos distinguir dos 
dimensiones en el análisis del concepto vida privada y sus alcances, esto es, un aspecto pasivo y otro activo. A través del primero, «se busca disponer de un ámbito de vida personal sustraído a cualquier tipo de intromisiones perturbadoras o, simplemente, no deseadas [...]. Por otra parte, la vida privada tiene una dimensión activa y dinámica que consiste en la posibilidad de conocer, acceder y controlar las informaciones que conciernen a cada persona» (Lagos Escobar, 2008: I37). Como dice Alberto Cerda, «ya no sólo se trata de la imposibilidad que tienen terceros de entrometerse en lo que me sucede, sino de la posibilidad que yo tengo de controlar la información concerniente a mi persona y excluirla del conocimiento de aquéllos, con antelación o aún una vez que ya se ha hecho circular tal información» (2003: 38).

Precisamente a ese último aspecto es al que se hace referencia en el voto disidente de la sentencia revisada, al indicar que la autodeterminación informativa del sujeto consiste en que cada individuo pueda determinar de qué forma comunica a otros información sobre sí mismo. A este respecto, se ha señalado que «el derecho a la autodeterminación informativa surge de la necesidad de control democrático y del derecho al acceso de la información; ambos aspectos son claves en una sociedad en que el poder informático es un poder invisible, y en que la tecnología puede ser fuente de manipulación de alcances insospechados» (Zúñiga, I997: 3 I2).

En virtud de lo anterior, la regulación vigente sobre protección de datos de carácter personal se hace cargo de tales consideraciones, entregando especial resguardo a determinados antecedentes que son considerados personales y, por tanto, quedan excluidos del conocimiento público. Si bien la ley I 9.628 sólo distingue entre datos personales y datos sensibles, la doctrina ha identificado otra categoría de datos que dicen relación con el contexto en que se tratan y la utilización que de ellos se hace, lo cual los puede transformar en datos sensibles. De este modo, si bien estos datos no son sensibles por naturaleza, tienden a ser sensibles en referencia al uso concreto que se les da y al marco en que se utilizan, y pueden convertirse en un riesgo para la vida privada de las personas. Dentro de esta categoría se sitúan los datos tributarios, las informaciones sobre solvencia crediticia o nivel de endeudamiento (Lagos Escobar, 2008: I42).

Entendemos que también caben en esa categoría las remuneraciones 
de los ejecutivos requirentes, es decir, puede ser que no compartan el carácter de dato sensible conforme con la definición de la ley I9.628, mas sí requieren un tratamiento especial.

\section{CONSIDERACIONES ESPECIALES SOBRE LA PUBLICIDAD DE LAS REMUNERACIONES DE LOS EJECUTIVOS REQUIRENTES}

En primer término cabe considerar lo dispuesto en la sentencia del Tribunal Constitucional rol 460, ${ }^{4}$ afirmando que el acceso de terceros a declaraciones de patrimonio de autoridades que ejercen una función pública ha de serlo para finalidades legítimas. En dicho sentido precisa:

La hermenéutica razonable, finalista y el principio de presunción de constitucionalidad, sostenidos reiteradamente por el Tribunal Constitucional, llevan a aseverar que la alusión al "conocimiento" y "consulta pública» en forma irrestricta de las declaraciones de patrimonio, debe ser entendida en el sentido que el acceso por terceros a esa información ha de serlo para las finalidades legítimas que la nueva normativa persigue, circunstancia esencial que exige, de todos los órganos del Estado involucrados, interpretarlas y aplicarlas con el objetivo señalado (STC 460, c. 3 I).

Esto es, no obstante el Tribunal declaró constitucional la consulta pública de las declaraciones de patrimonio de las autoridades y funcionarios públicos, lo hizo en el entendido que el acceso a dicha información debía siempre permitirse con estricta consideración de las normas sobre resguardo de la vida privada contenidas en la Constitución.

Ahora bien, para el presente análisis son pertinentes las consideraciones efectuadas en el mismo fallo por el (ex) ministro del Tribunal Constitucional Juan Agustín Figueroa al fundamentar su voto disidente. Sobre el particular, la disidencia se funda precisamente en la circunstancia que, en su entender, la situación patrimonial de una persona cabe, en principio, en el campo de la vida privada de la persona, recordando que el patrimonio es uno de los atributos de la personalidad y, en razón de ello, demanda el respeto y protección del ordenamiento jurídico y, por tanto, el conocimiento por parte de terceros de dichos antecedentes

4. Control de constitucionalidad del proyecto de ley que estableció la obligación de ciertos funcionarios de declarar su patrimonio. Ley 20.088 . 
privados debe considerarse excepcional. La disidencia termina afirmando que el acceso público y sin cortapisas a declaraciones patrimoniales que deberían hacer aquellos que desempeñan las señaladas funciones públicas, desconoce su derecho a la vida privada, por lo cual las normas observadas deberían ser declaradas inconstitucionales.

$\mathrm{Si}$, conforme lo señalado, la publicidad de las remuneraciones de personas que ejercen funciones públicas y, que en razón de ello, el umbral de exigencia es más alto cediendo incluso a revelar aspectos que en otras circunstancias se considerarían privados, genera opiniones encontradas, con mayor razón en el caso particular se comparten dichas aprensiones. Los ejecutivos requirentes no son funcionarios públicos y, además, se rigen por las disposiciones contenidas en el Código del Trabajo, entre las cuales, como dijimos, resultan de relevancia y absoluta aplicación aquellas que dan protección a la vida privada de los trabajadores contenidas en los artículos $5 \cdot^{\circ}$ y I $54 .^{\circ}$ bis.

Ahora bien, en el caso de aquellas personas que ejercen una función pública se admite que se den a conocer ciertos aspectos de su vida privada en virtud de los principios de transparencia, probidad y en razón de las funcionas que desempeñan, atendido el interés público, denominado en el derecho comparado como relevancia pública de la información:

[En relevancia pública de la información] también desempeña un papel destacado el carácter público o privado de las personas involucradas. Como se afirma tanto por la doctrina como por la jurisprudencia extranjera, las personas que desempeñan alguna función pública, o que se han expuesto voluntariamente en el ámbito de lo público, no pueden sino aceptar y reconocer necesariamente un ostensible menor grado de protección de la privacidad en sus vidas (Anguita, 2009: 335 ).

En esa misma lógica, la Corte Interamericana de Derechos Humanos ha precisado que «tratándose de funcionarios públicos, de personas que ejercen funciones de una naturaleza pública y de políticos, se debe aplicar un umbral diferente de protección, el cual no se asienta en la calidad del sujeto, sino en el carácter de interés público que conllevan las actividades o actuaciones de una persona determinada». ${ }^{5}$

Sin embargo, los ejecutivos requirentes no son en ningún caso funcio-

5. Corte Interamericana de Derechos Humanos, caso Palamara vs. Chile (2005), párr. 84. 
narios públicos; es más, su relación laboral se rige por las disposiciones del Código del Trabajo y, en razón de ello, le son plenamente aplicables dichas normas. Desconocer la protección para el caso particular de estos ejecutivos resulta contrario a la igualdad ante la ley, conforme señalaremos a continuación.

\section{VULNERACIÓN DEL DERECHO A LA IGUALDAD ANTE LA LEY}

Resulta relevante señalar que el Tribunal, al declarar la constitucionalidad de los artículos Io. ${ }^{\circ}$ letra h) y $33 .^{\circ}$ letra b) de la Ley de Transparencia, no se hizo cargo del argumento de los requirentes en el sentido que dichas disposiciones para el caso concreto derogaban los artículos $50^{\circ} \mathrm{y}$ I $54 .^{\circ}$ bis del Código del Trabajo.

En este sentido, al estar regidos los trabajadores de TVN por el Código del Trabajo y, asimismo, estar obligada la empresa a revelar y publicar información sobre sus remuneraciones, se excluye arbitrariamente a dichos trabajadores de la protección asignada por la ley, produciendo asimismo una vulneración al derecho a la igualdad.

En la doctrina se han elaborados diversos criterios de fondo que apuntan a dilucidar cuándo una diferencia es arbitraria. Así por ejemplo, como señalan Verdugo, Pfeffer y Nogueira, la igualdad ante la ley «se trata de una igualdad jurídica que impide que establezcan excepciones o privilegios que excluyan a unos de lo que se concede a otros en iguales circunstancias» (I994: 208). En otras palabras, la igualdad jurídica se traduce en la imposibilidad de establecer diferencias entre iguales, estableciéndose la opción del constituyente que a fin de que todos los que se encuentran en una misma categoría, situación o circunstancia, sean tratados de manera similar por la norma legal, sin que existan entre ellos privilegios o diferencias arbitrarias.

De acuerdo a lo anterior, Alejandro Silva Bascuñán señala que se violaría la igualdad ante la ley si se excluye a determinadas personas, que se individualizaren, de una situación jurídica concreta sobre la base de tomar en cuenta exclusivamente su calidad personal, pero no iría en contra de tal igualdad si el legislador genéricamente describe situaciones que colocan a ciertas personas en una posición jurídica diferente respecto de otras, aunque, circunstancialmente, pudiera reunirse tal posición tan sólo respecto de una sola persona (Silva Bascuñan, 2002: I09). 
Estos criterios han sido desarrollados por la jurisprudencia del Tribunal entendiendo que para determinar si un acto es arbitrariamente discriminatorio, se requiere un análisis en tres pasos. En primer lugar, identificar la finalidad del acto potencialmente arbitrario. En segundo lugar, analizar si esa finalidad tiene respaldo en nuestro ordenamiento jurídico. Y, finalmente, debe evaluarse la racionalidad y proporcionalidad del acto en cuestión, en relación con su finalidad. ${ }^{6}$ Así, el acto resultará ser arbitrariamente discriminatorio si es caprichoso (es decir, no tiene finalidad razonable), si su finalidad está proscrita por el ordenamiento jurídico o si no es adecuado respecto a la finalidad perseguida.

Pues bien, la aplicación que el Consejo hace de las normas impugnadas implica una evidente discriminación arbitraria, infringiendo la garantía de la igualdad ante la ley, ya que genera un trato diferenciado al privar a un grupo - específicamente los ejecutivos requirentes- de manera arbitraria del derecho fundamental a la igualdad ante la ley.

En otras palabras, se otorga un trato desigual a los afectados, en relación con quienes ejercen funciones similares en el sector privado, ya que para éstos «el ejercicio de las facultades que la ley le reconoce al empleador, tiene como límite el respeto a las garantías constitucionales de los trabajadores, en especial, cuando pudieran afectar la intimidad, la vida privada o la honra de éstos». ${ }^{7}$

Ahora bien, el principio de igualdad no se reduce a la prohibición de tratos desiguales sin fundamento racional. La igualdad ante la ley tiene un carácter relativo y proporcional. En efecto, cuando se establece una diferenciación basada en grupos de personas o una diferenciación referida a circunstancias que se traduce en tratamiento desigual de personas, se debe desarrollar un análisis atendiendo, además, al principio de proporcionalidad (Nogueira Alcalá, 2006: 8I 2).

Este criterio ha sido desarrollado por el Tribunal Constitucional alemán, el cual sostuvo que ante una eventual contravención al principio de igualdad mediante una ley, se deberá efectuar un examen que comience la prohibición de la arbitrariedad y alcance hasta la exigencia de proporcionalidad; de este modo el tribunal señala que «cuando un grupo de destinatarios de una norma es tratado de manera distinta, en

6. Véase por ejemplo, Sentencia del Tribunal Constitucional rol I4 I 4, considerando I $7 .^{\circ}$

7. Artículo $5 .^{\circ}$ inciso I. ${ }^{\circ}$ del Código del Trabajo. 
comparación con otros destinatarios de la misma, a pesar de que entre los dos grupos no existan diferencias de tal tipo y de tal peso que puedan justificar el trato diferente». ${ }^{8}$

Por lo tanto, para que la carga que impone el Consejo para la Transparencia a los ejecutivos requirentes - por el sólo hecho de serlo- resulte lícita, no basta sólo con el fin que con ella se persiga sea lícito —en el caso concreto el principio de probidad—, sino que, además, las consecuencias jurídicas resulten asimismo adecuadas. Cuestión que no ocurre en los hechos, puesto que los ejecutivos resultan completamente despojados de protección por el sólo hecho de desempeñar funciones en una empresa pública.

Asimismo, cabe agregar que la interpretación que el Consejo para la Transparencia realiza de la Ley de Transparencia no supera el requisito de proporcionalidad, el cual conforme señala la doctrina y así ha señalado el Tribunal debe realizarse, no respecto de los bienes en abstracto, sino considerando específicamente, en el caso concreto, las probabilidades y magnitudes del daño y de los beneficios previsibles con la medida legal en análisis.

En este sentido, la intromisión a la privacidad de dichos ejecutivos no resulta justificada ni constituye la única alternativa que tiene el sistema para resguardar la probidad de las empresas públicas puesto que, como hemos señalado, la reforma del 2005 permite a las comisiones investigadoras de la Cámara de Diputados solicitar dichos antecedentes dentro de un proceso de investigación.

Por tanto, la aplicación de dichas normas al caso concreto no supera el examen de proporcionalidad que el Tribunal debió realizar al momento de revisar la cuestión sometida a su conocimiento.

\section{LIBERTAD ECONÓMICA}

La norma constitucional del artículo I9. ${ }^{\circ}$ número 2 I inciso $2 .^{\circ}$ establece que podrá autorizarse el desarrollo de actividades empresariales o la participación en ellas al Estado o sus organismos.

La actividad empresarial del Estado presenta una doble naturaleza:

8. Sentencia del Tribunal Constitucional Federal alemán, Primera Sala, BVerfGE 55 $72(88)$, de fecha 7 de octubre de 1980 . 
por una parte satisface una necesidad pública mediante la prestación de servicios o de producción o distribución de bienes, pero, por otra, está sujeta a un régimen jurídico particular, por regla general, de derecho privado. En tal condición se distinguen dos aspectos claramente diferenciados, por una parte una naturaleza pública y por la otra una naturaleza privada. La primera emana de su inserción en la Administración del Estado. En palabras de Enrique Silva Cimma:

Las empresas públicas creadas por ley, en cuanto órganos del Estado autorizados para desarrollar actividades empresariales, constituyen un verdadero servicio público, pues es posible encontrar en ellas todos los elementos que configuran a dichos organismos: una función considerada como obligatoria, recursos públicos y régimen jurídico especial (1995:195).

En este sentido la LOCBGAE trata a estas empresas como órganos de la Administración del Estado.

Existe junto a esta naturaleza pública un aspecto privado que nace que la relación de estas empresas con las otras empresas que compiten en el mercado, lo cual implica que su régimen sea el de derecho común al regular la actividad que desarrollan.

Así, estas empresas se rigen por el principio de legalidad, es decir, no pueden actuar sin atribuciones legales, expresas y previas, de modo que su accionar no puede contravenir el ordenamiento jurídico. Su fuente de regulación es el numeral 2 del inciso $4 .{ }^{\circ}$ de artículo $65 .^{\circ}$ de la Constitución. Sin embargo, en tanto entes regidos por el derecho privado, se sujetan, en cambio, al derecho común aplicable a los particulares. Estas normas se articulan bajo un concepto contrapuesto al anterior, pues se rigen por el principio de la autonomía de la voluntad, conforme el cual pueden realizar todo aquello que la ley no les prohíbe de manera expresa (Lagos Escobar, 2008).

Sobre la naturaleza de TVN, su Estatuto señala que es una empresa que tiene iguales derechos, obligaciones y limitaciones que una concesionaria de servicio de televisión constituida como persona jurídica de derecho privado. De ahí se sigue que están sujetas a las mismas normas financieras y tributarias que rigen para las sociedades anónimas abiertas, sin que se les apliquen las normas de régimen y administración económica que rigen a las empresas del Estado. 
En cuanto a la Ley de Transparencia, como ya se indicó, su aplicación es excepcional porque requiere alusión expresa y porque sólo se le aplican los artículos $3 .^{\circ}$ y $4 .^{\circ}$ De hecho, la ley expresamente señala que a TVN se le aplican dichas disposiciones, aun cuando la ley respectiva (Estatuto de TVN) disponga que es necesario mencionarlas expresamente para quedar sujetas a la regulación de otras leyes. Por lo tanto, para que se le pudiera aplicar el artículo $33 .^{\circ}$ de la ley que establece la facultad del Consejo de pronunciarse sobre la denegación de información, la ley debió señalarlo expresamente, cuestión que no hizo.

A mayor abundamiento, una revisión de la historia de la Ley de Transparencia permite concluir que la decisión de incluir a las empresas públicas en su aplicación fue consecuencia de un acuerdo político explícito, que implicaba someterlas a un régimen especial y excluirlas de las reglas comunes de transparencia pasiva y activa aplicables a las generalidad de los órganos de la Administración. Asimismo, el artículo 2. ${ }^{\circ}$ de la ley revela que esta disposición distingue claramente en sus incisos entre el estatuto común aplicable a la generalidad de los órganos de la Administración (establecido en el artículo ı. ${ }^{\circ}$ ) y los regímenes especiales de transparencia (establecidos en los artículos siguientes) para ciertos órganos específicos de la Administración y otros órganos del Estado. Específicamente tratándose de los deberes de transparencia pasiva, el objetivo de la ley era homologar los estándares de publicidad de las empresas públicas y las sociedades anónimas abiertas (Pardow y Vallejo, 2010: 220-43).

Por lo tanto, la intervención que el Consejo hace sobre el funcionamiento del canal significa adicionarle un control extra sin que exista una norma legal habilitante conforme lo establecido en el artículo i9. ${ }^{\circ}$ número 2 I de la Carta Fundamental.

En razón de lo previamente señalado, el voto de la mayoría presenta una seria deficiencia al confundir la naturaleza pública de TVN y su naturaleza privada. Esta confusión se reflejada en el considerando sexagesimoctavo al señalar: "Las limitaciones establecidas se encuentran en íntima relación con la naturaleza jurídica de Televisión Nacional de Chile. Consecuencia de lo anterior es la circunstancia de que la administración de dicha corporación la ejerce un directorio compuesto de siete miembros, seis de los cuales son designados por el Presidente de la República, con acuerdo del Senado y el presidente será de libre designación 
del Ejecutivo». Este considerando es fundamental para graficar como la mayoría no logra distinguir entre la función pública que cumple TVN y respecto de la cual se justifica plenamente que el nombramiento de los altos directivos del canal se realice a través de un proceso político que involucre a la Cámara Alta, pero una cuestión distinta es la intención del constituyente de someter a estas empresas a la misma normativa que rige a todas las empresas del sector.

En este sentido, la competencia dentro de los canales de televisión y el hecho que TVN no pueda ser obligado a proporcionar al Gobierno servicio alguno sin la debida compensación económica, la cual debe ser igual al costo que le demandaría igual prestación de otra concesionaria de servicio de televisión, reafirma que en la génesis de su creación estaba previsto dejar a este canal regido por las mismas normas que se aplican al resto de sus competidores.

Por último, es pertinente señalar que la mayoría realiza una interpretación restringida de las normas aplicables, modificando así el sistema integral que la Constitución ha diseñado para los casos en que autoriza que el Estado realice actividades empresariales. Con ello la sentencia se inclina peligrosamente en defensa de la transparencia desconociendo, el diseño constitucional para las empresas del Estado.

\section{CONCLUSIONES}

De acuerdo a lo señalado precedentemente podemos concluir que el asunto sometido a la decisión del Tribunal constituye un conflicto constitucional y no se reduce un asunto de mera legalidad.

Como hemos señalado, la interpretación del Consejo infringe tres garantías constitucionales, a saber, el derecho a la vida privada, la igualdad ante la ley y la libertad económica. Así también, el razonamiento del Tribunal, al rechazar el requerimiento, vulnera dichas garantías.

De este modo, la vulneración a la vida privada de los ejecutivos de TVN se configura al determinarse por parte del Consejo la publicación de su remuneración, constituyendo una intromisión ilegítima en la esfera de su privacidad y afectando su derecho a la autodeterminación informativa.

Por otra parte, se afecta también la garantía constitucional de igualdad ante la ley, dado que dichos ejecutivos no son funcionarios públicos 
y por tanto, su relación laboral se rige por el Código del Trabajo, al obligarse a la empresa a revelar y publicar información sobre sus remuneraciones, se excluye arbitrariamente a dichos trabajadores de la protección asignada por la ley, produciendo asimismo una vulneración al derecho a la igualdad.

En lo que respecta a la afectación de la libertad económica, la intervención que el Consejo efectúa sobre el funcionamiento de TVN implica desconocer la aplicación restrictiva a su respecto de la Ley de Transparencia y adicionarle un control extra sin que exista una norma legal que así lo faculte, según lo asegurado en la Constitución, desmejorando la posición de la empresa como prestador de un servicio televisivo respecto del resto de los canales que conforman dicho mercado.

Adicionalmente, el voto de mayoría desconoce la sistematicidad de la Constitución Política, dado que confunde la procedencia de dos principios que rigen en el ordenamiento: probidad y transparencia. Como mencionamos, el principio de probidad está contenido en el artículo $8 .^{\circ}$ de la Constitución y el principio de transparencia se encuentra recogida en la ley 20.285. Con el razonamiento del Tribunal lo que se hace es trasladar la transparencia desde una disposición legal a una disposición constitucional, ampliando su campo de aplicación, convirtiéndose el Tribunal en un legislador positivo, cuestión que, como el mismo ha señalado, se encuentra proscrita.

Finalmente, no podemos dejar de señalar que resulta incoherente la aplicación simultánea de dos preceptos constitucionales: el artículo $8^{\circ}$, por una parte, que establece la publicidad de los actos de los órganos del Estado; y el artículo 52. número I letra c), por la otra, que faculta a la Cámara para disponer la citación de determinados representantes de las empresas del Estado para las funciones de fiscalización que le son propias. Sobre el particular, el Tribunal debió haber realizado una interpretación útil de la reforma constitucional del 2005 , dándole sentido práctico a las nuevas facultades que se le entrega a la Cámara de Diputados, puesto que tal reforma no hubiese sido necesaria si los antecedentes objeto de éstas, pudiesen haber sido solicitados por cualquier particular vía Ley de Transparencia. 


\section{REFERENCIAS}

Anguita, Pedro (2009). «Jurisprudencia constitucional sobre el derecho a la propia imagen y a la vida privada en Chile (I98I-2004). Un intento de sistematización». Disponible en <http://www.derechoshumanos.udp.cl/wp-content/uploads/2009/o7/jurisprudencia.pdf >.

CERDA, Alberto (2003). «Intimidad de los trabajadores y tratamiento de datos personales por los empleadores». Revista Chilena de Derecho Informático, 2: 35-59. Disponible en <http://www.derechoinformatico.uchile.cl/index.php/RCHDI/article/viewArticle/I0645/I I373>.

Corral, Hernán (2000). "Configuración jurídica del derecho a la privacidad II. Concepto y delimitación». Revista Chilena de Derecho, 2 (2).

Correa Sutil, Jorge (200I I). Jurisprudencia del Tribunal Constitucional en materia de igualdad ante la Ley. ¿Saliendo de la pura tautología? Anuario de Derecho Público (Universidad Diego Portales).

Lagos Escobar, Ricardo (2008). Doctrina Constitucional del Presidente Ricardo Lagos Escobar (2000-2006). Santiago: Ministerio Secretaria General de la Presidencia.

Nogueira Alcalá, Humberto (2006). «El derecho a la igualdad ante la ley, la no discriminación y acciones positivas». Anuario da Facultade de Dereito (Universida de da Coruña).

Novoa Monreal, Eduardo (I989). Derecho a la vida privada y libertad de información. Un conflicto de derechos. México: Siglo xxI.

Pardow, Diego y Rodrigo Vallejo (20I0). «El traje nuevo del emperador: Una revisión de la Jurisprudencia del Consejo para la Transparencia respecto de las empresas públicas». Anuario de Derecho Público (Universidad Diego Portales).

Silva Bascuñán, Alejandro (2002). Tratado de derecho constitucional. Tomo VIII. Santiago: Jurídica.

Silva Cimma, Enrique (1995). Derecho administrativo chileno y comparado. El servicio público. Santiago: Jurídica.

Suárez Crothers, Christian (2000). El concepto de derecho a la vida privada en el derecho anglosajón y europeo. Revista de Derecho (Valdivia), II: IO3-I 20.

Verdugo, Mario, Emilio Pfeffer y Humberto Nogueira (I994). Derecho constitucional. Tomo II. Santiago: Jurídica. 
Vivanco, Angela (2006). Curso de derecho constitucional. Tomo II. Santiago: Ediciones Pontificia Universidad Católica de Chile.

ZúÑIga, Francisco (I997). «El derecho a la intimidad y sus paradigmas». Ius et Praxis, 3 (I).

\section{SOBRE LAS AUTORAS}

Ana María Muñoz Massoun es abogada de la Pontificia Universidad Católica de Chile. Profesora Instructora de la cátedra de Derecho de la Comunicación de la Facultad de Comunicaciones de la misma casa de estudios. Magister en Derecho Público (c) de la Universidad de Chile. Su correo electrónico es <anitamuma@hotmail.com>.

Montserrat Castro Hermosilla es abogada de la Universidad de Chile. Ayudante del Programa de Antropología Jurídica de la misma casa de estudios. Magister en Derecho Público (c) de la Universidad de Chile. Su correo electrónico es <montserratcastroh@gmail.com>.

Este trabajo fue recibido el I 4 de agosto de 20 I 2 y aprobado el I I de septiembre de 2012. 